\title{
Las metamorfosis de los mitos de Ícaro y Dédalo: una correlación de las estéticas de Publio Ovidio Nasón y James Joyce
}

\author{
Cruz Alejandro HeRnández Rico \\ Universidad Nacional Autónoma de México
}

\begin{abstract}
En este artículo se expone cómo, a pesar de pertenecer a épocas y cosmovisiones distintas, tanto Ovidio en sus Metamorfosis como James Joyce en su Retrato del artista adolescente utilizan el mito del laberinto de Dédalo como metáfora de la forma de sus respectivas obras y ven en el mito de Ícaro el símbolo del artista vanguardista: aquel que debe alejarse del orden establecido en pos de la novedad.
\end{abstract}

PALABRAS CLAVE: Dédalo, Ícaro, James Joyce, Ovidio, Metamorfosis, Retrato del artista adolescente, laberinto, stream of consciousness.

This article examines how, despite belonging to different times and worldviews, both Ovid in his Metamorphoses and James Joyce in A portrait of the Artist as a Young Man use the myth of the labyrinth of Daedalus as a metaphor for the shape of their respective works and see the myth of Icarus as a symbol of the avant-garde artist: one who must depart from the established order in pursuit of novelty.

KEY WORDS: Daedalus, Icarus, James Joyce, Ovid, Metamorphoses, A Portrait of the Artist as a Young Man, labyrinth, stream of consciousness.

En su Introducción a las Metamorfosis de Ovidio, Rubén Bonifaz Nuño realiza una bella y significativa descripción de cómo debió haber sido la mirada que Ovidio lanzaba sobre el universo:

[El hombre contempla cómo] fluyen las apariencias como el caudal de un río sin fuente, sin salida hacia mar alguno; toda imagen es errante, y no para un punto en su deslizamiento hacia otra imagen... Cada momentánea presencia empuja sin consideración a otra que la precedió, y es, a su turno, empujada por otra que la persigue.

Corriente absurda de imágenes y de momentos; de figuras y de tiempos que se acosan y se persiguen como aguas precipitadas de un torrente (VII).

Al parecer, esta cosmovisión inspirará en el poeta la forma que necesita para su poema. Bonifaz Nuño explica que Ovidio muestra sus intenciones estéticas desde los primeros versos de las Metamorfosis: "¡Del primer origen del mundo / el perpetuo carmen haced bajar a mis tiempos!” (I: 3-4). Según Bonifaz Nuño la ambición decla- 
rada de Ovidio sería “obtener la iluminación de las esferas superiores para escribir con ella un poema cíclico, sin interrupciones, perpetuo, cuyo desarrollo progrese siguiendo el orden marcado por el desenvolvimiento del tiempo" (XIII).

Por otro lado, James Joyce, inspirado en la tradición escolástica de Tomás de Aquino y Aristóteles, sabe que se puede observar y apreciar el mundo material a través de los sentidos: "Tomás de Aquino encontró significancia espiritual en la realidad existente en la naturaleza: uno debería ir fuera de su mente, hacia el cuerpo, hacia los sentidos, hacia lo físico, para descubrir tanto al propio ser como a Dios" (Parkinson: 177). En este sentido, Langdon Hammer afirma: "Joyce takes a de-idealizing approach... to psychological experience, insisting on the material base of our feelings" (11). Sin embargo, Joyce, como cualquier lector de su obra puede comprobar, tiene un ánimo protestante (no sólo en un sentido religioso) y es por esa razón que hay momentos en que pareciera llevarse por una lógica calvinista: "para los calvinistas, el progreso en la sabiduría es el progreso de la mente que se aparta del mundo hacia Dios" (Parkinson: 173). Quizás una de las convenciones calvinistas con más repercusión en la obra de Joyce sea la idea del "mundo como un laberinto de símbolos". ${ }^{1}$ Este ir de la mente al cuerpo y viceversa tendrá resonancias del "fluir" y "refluir" que Ovidio construye en su noción de arte como se verá más adelante. En Joyce el lector no sólo asiste al movimiento de las formas en la naturaleza sino al desarrollo de un individuo: "El retrato del artista adolescente no narra sino que dibuja una larga presencia prolongada" (Marichalar: XVII). En el mismo sentido Hammer agrega: "Baby Tuckoo apprehends his world and in time becomes Stephen Dedalus. [Language] is the instrument of his self-making" (11).

Sin embargo, a pesar de las diferencias filosóficas y culturales ambos autores desarrollaron estéticas análogas a partir de los mismos arquetipos: ambos utilizan el mito del laberinto de Dédalo como metáfora de la forma de sus respectivos textos y ambos ven en el binomio Dédalo-Ícaro el epítome del Artista.

\section{El laberinto}

En su ensayo Daedalus in The Labyrinth of Ovid's Metamorphoses Barbara Pavlock afirma que Ovidio usa el mito del laberinto de Dédalo para construir una metáfora que explica la forma e intención de sus Metamorfosis en contraste con la visión del arte que Virgilio desarrolla en la Eneida. ${ }^{2}$

\footnotetext{
${ }^{1}$ James Joyce comparte junto con Charles Baudelaire la noción de la naturaleza como un laberinto de símbolos; dicha visión puede apreciarse con claridad en el Ulysses, en donde el sistema de correspondencias entre microcosmos y macrocosmos, así como la relación entre el hombre y el body politic, cobra importante significancia. Baudelaire desarrolla esta idea en su famoso soneto Correspondances. No obstante, el paralelismo entre las obras de ambos autores arroja material para otro ensayo. Si se tiene interés por el tema se puede consultar el trabajo de William York Tindall James Joyce and the Hermetic Tradition.

${ }^{2}$ El excelente trabajo de Barbara Pavlock contrasta la metáfora que Ovidio construye con la versión de Virgilio y por tanto con su visión del arte. El análisis de Pavlock diferencia la forma de la Eneida (maze-
} 
De acuerdo con Pavlock, el símil épico en el que Ovidio compara al laberinto de Creta con el Meandro frigio en el libro VIII de las Metamorfosis pone en práctica su ars poetica:

Dédalo, por su ingenio en el arte de hacer, celebérrimo,

Pone la obra, y turba las marcas, y con revuelta los ojos

Guía al error, con ambage de vías variadas.

No de otro modo, el Meandro frigio en sus líquidas ondas

Juega y con resbalar ambiguo fluye y refluye

Y yendo a su encuentro, mira sus ondas que habrán de venirle,

Y ora hacia sus fuentes, hacia el abierto mar ora vuelto,

Ejercita inciertas aguas, así Dédalo colma

De error las innúmeras vías, retornar apenas él mismo

Pudo al umbral (VIII: 159-168).

Pavlock sugiere que la forma misma de las Metamorfosis es la de un "meandro", o, como el propio Ovidio agrega, "un resbalar ambiguo" que "fluye y refluye": "The labyrinth perfectly characterizes the form of his own poem, its fluid movement from tale to tale and clever, if tenuous, transitions from one book to another. The adjective ambiguus furthermore points to the unexpected twists and turns in this poem. Like the Meander as Labyrinth, Ovid's poem is ever-changing, shifting in direction" (145-146).

Ovidio quiere representar a la naturaleza en su misma esencia y encuentra esta esencia en el perpetuo movimiento universal de las formas. El poeta se pregunta cuál sería la forma que pudiese "capturar" o "fijar" este incesante movimiento. Al respecto, Rubén Bonifaz Nuño asegura que: "La admisión de esa forma inmóvil a mitad del condenado movimiento universal, la esperanza de la existencia de algo que en el cerco de ese movimiento se mantenga y se afirme, es el asunto que Ovidio desarrolla en sus Metamorfosis" (X).

Barbara Pavlock propone que Ovidio intenta diferenciar la forma de su poema épico de la forma de la Eneida:

The ekphrasis of the temple doors is a kind of emblem of Vergil's epic, for the poet had prophesied in the Georgics that he would in the future construct a temple to honor the achievements of Augustus (3:10-39). Here [Vergil] refers to the labyrinth periphrastically: hic labor ille domus es inextricabilis error (6: 27). It is well known that Vergil makes a striking etymological play by deriving the Word "labyrinth" from the noun labor and thus associates the structure with toil and struggle (144).

Para Pavlock, la estructura del poema épico de Virgilio, un maze, se ciñe a un modo de representación que requiere demasiadas convenciones y que Ovidio encuentra rígido: 
"While Vergil's epic has a maze-like symmetry, Ovid's poem is labyrinthine in its emphasis on fluid process rather than intricate structure" (146). Según Pavlock, para Ovidio las Metamorfosis son este "jugar" y "resbalar ambiguo": "Ovid... defines his poetics by contrast to Vergil in his description of the playfulness of the Meander ( $l i-$ quidis... in undis/Ludit ). Lusus is an important Augustan literary concept, which characterizes Ovid's elegiac poetry" (146). A diferencia de su predecesor, Ovidio prefiere jugar con las formas y modelos en vez de ejercitar una complicada construcción. Para Ovidio este jugar con las formas es la característica del estilo que él propone: "The adjective liquidus describing the waves of the meander further connects the simile to poetics, for the word occurs among Roman writers to characterize afluid, smooth style" (146). Ovidio busca un estilo suave y fluido que le permita presentar al hombre el continuo cambio de las formas en el universo.

James Joyce también utiliza a Dédalo y su laberinto para desarrollar su propia visión del arte. De hecho, Joyce hace una reescritura del ars poetica de Ovidio ajustándola a sus necesidades como novelista. El retrato del artista adolescente comienza con un epígrafe extraído de las Metamorfosis: "et ignotas animus dimitit in artes" (VIII: 188). El paratexto advierte al lector que la novela guarda una estrecha relación con la obra de Ovidio y que ésta resuena poderosamente en la obra del autor irlandés. Esta sospecha se confirma en el momento en que percibimos que Joyce nos narra el despertar artístico del joven Stephen "Dedalus". La forma del Künstlerroman o novela de crecimiento de un artista está pensada al igual que el poema de Ovidio en términos de un "flujo". En la novela el "flujo" de la conciencia se logra a través del "monólogo interior", técnica que, dicho sea de paso, evolucionará en lo que luego Joyce denominará "stream of consciousness" (nótese la connotación del término anglosajón "stream"). Joyce, a diferencia de Ovidio, no quiere representar a la naturaleza cambiante del mundo, sino que quiere poner a su lector ante el flujo de una conciencia que se construye y se transforma en la medida en que aprende el lenguaje para nombrarlo. Stephen Dedalus lo explica mientras habla de estética con uno de sus compañeros del college: "[en la obra de arte] the personality of the artist [is], at first a cry or a cadence or a mood and then a fluid and a lambent narrative..." (Joyce: 217). En el mito, Dédalo utiliza sus habilidades creativas para construir un laberinto que le permita contener al minotauro, sin embargo, el propio artesano lo vuelve tan complicado que por poco se pierde dentro de su propia trampa. Como afirma Antonio Marichalar en su prólogo a El retrato del artista adolescente: "Esteban Dédalus, monstruo de su laberinto, [se agita] en la angustia de su propia turbación, queriendo rebasar los imprecisos límites de su existencia" (XXII). El laberinto, en este caso, se encuentra dentro de la mente del personaje, de hecho, es el mismo pensamiento en evolución. Así que las curvas que va tomando la narración, los meandros de la historia, son reflejo del proceso de cognición del personaje de Joyce. Son estas curvaturas las que van a construir la personalidad del artista y por tanto su retrato. En las Metamorfosis, como se dijo antes, los meandros son los cambios constantes en la narración que nos llevan de un cuento a otro; en la novela de Joyce las curvaturas responden al proceso digresivo del pensamiento, y 
aunque se apartan por momentos de la narración principal, vuelven para retomar el hilo conductor de la obra. Es en este sentido como podríamos entender la reinterpretación que Joyce hace del "flujo" y "reflujo" de la corriente, en este caso el pensamiento. Aunque también, puede entenderse como esta suerte de ida y venida de la mente al mundo exterior y al revés.

Tanto Ovidio como Joyce buscan transformar su meandro en un reflejo de su estilo. El primero se propone representar su labor poética como un "proceso fluido" que va tomando forma a la par de ir "jugando" y reinventándose. De hecho, la raíz etimológica de "laberinto" en Ovidio debe rastrearse al juego de palabras que el poeta crea entre los términos latinos labor y lusus. Como dice Barbara Pavlock, quizás Ovidio tenía en mente el tipo de "meandro" que Séneca el joven propone cuando dice "poetarum omnium exercitatio et ludus" (143). Para Séneca la poesía es una "práctica (labor)" y un "juego (lusus)": "Lusus is an important Augustan literary concept, which characterizes Ovid's elegiac poetry. Here, Ovid extends this poetic "play" to epic, as he incorporates light subjects not normally included in traditional epic and often parodies more serious subject matter" (Pavlock: 146). Joyce como novelista emula a Ovidio en cierto modo y vuelve los temas mundanos el asunto de su épica. Joyce también juega con la forma de la novela e incorpora el elemento paródico para crear una historia de alcances épicos a partir de hechos aparentemente triviales. Si como asegura Pavlock, Ovidio juega con diferentes niveles de entonación poética para generar el efecto de cambio y transformación (flujo y reflujo); James Joyce juega con el lenguaje por medio del pastiche y del collage. Desde el "Once upon a time and a very good time it was there was a moocow" (19) que da inicio a la novela hasta las entradas del diario que la concluyen (249), el libro de Joyce es un montaje de diferentes registros del habla que dan la ilusión de un flujo de conciencia que va tomando forma a la vez que se desarrolla en el tiempo.

Ovidio ve en el laberinto de Dédalo la metáfora perfecta de su propia tarea como poeta y Joyce encuentra en Ovidio la forma que necesita su novela para desarrollar sus propias inquietudes artísticas. Quizá la diferencia entre el poeta latino y el novelista irlandés radica en que Joyce también le otorga un sentido metafórico al minotauro, pues como afirma Antonio Marichalar, Stephen Dedalus es el monstruo de su propio laberinto.

\section{El mito de Ícaro}

A pesar de que Ovidio ve en Dédalo al arquetipo del artista y en el laberinto la forma que debe tomar su poesía, es en el mito de Dédalo e Ícaro en donde éste desarrolla su idea estética más importante.

Respecto a la validez y las causas que podrían provocar una "metamorfosis" de acuerdo con la cosmovisión de Ovidio, Ruben Bonifaz Nuño dice:

La absoluta mayoría de las metamorfosis dispuestas por la divinidad proviene en su origen de un estado de conciencia o inconsciencia que alguien tiene de sí mismo; en 
otras palabras, de la piedad o de la impiedad de alguien... el autoconocimiento le habrá de vedar, por una parte, ser osado de rivalizar con los dioses; no le permitirá, por la otra, descender al nivel inferior de las bestias o las cosas. Con la ignorancia vencida, el hombre se sobrepondrá sin dificultad a su arrogante soberbia, y no se dejará caer en aquello que por su propia índole ha superado. Será hombre, y dejará a las naturalezas superiores e inferiores lo que les corresponde por esencia... Cuando un ser, por lo común un ser humano, demuestra conocerse a sí mismo, se prohíbe proponerse, sin el auxilio de los dioses, finalidades que se encuentran fuera de su naturaleza, con lo cual se manifiesta piadoso; por lo contrario, en caso de ignorarse, trata de continuo de igualarse con aquellos, mostrándose, así, impío, y exponiéndose a represalias y castigos (XXIV).

En este sentido, Barbara Pavlock considera que, en un principio, pareciera que Ovidio atribuye a los ánimos de Dédalo un carácter negativo y funesto. Pues tilda de "dañosas" (Ovidio, VIII: 215) las artes de Dédalo. Tanto Bonifaz Nuño como Pavlock ven en la caída de Ícaro un castigo a la soberbia o hibris del artesano: "In book 8, Daedalus shows hibris by failing to invoke the gods at all before beginning his bold flight or at any time in the episode" (Pavlock: 151), y Nuño: "En cuanto a Ícaro y Dédalo que pretenden asumir la facultad del vuelo, violando los límites de su naturaleza, no consiguen otra cosa que la muerte y la desventura. Lo único que pueden hacer es utilizar un remedo de alas impotentes bajo los fuegos del cielo, y su mutación en alas de dioses o en aves no pasa de ser incompleta y externa y desafortunada" (XXV-XXVI).

Para entender el concepto de hibris tal cual como lo entendían Ovidio y sus contemporáneos, es preciso entender el concepto del "medio camino", que de alguna manera explicita en qué sentido Ovidio desafía las concepciones de su tiempo. Antes de narrar la caída de Ícaro, Ovidio introduce el concepto del "medio camino":

\footnotetext{
Después que la última mano al intento

Fue impuesta, el mismo artífice equilibró en las alas gemelas

El cuerpo suyo, y pendió en el aura movida.

Instruye también a su hijo, y: "Que corras por medio camino, Ícaro - habla- aconsejo; porque no, si vas más abajo,

La onda agrave las plumas; las abrase, si más alto, el fuego.

Entre ambos vuela (VIII: 200-206).
}

Pavlock encuentra en esta idea una convención de la época augusta que advierte al artista de los peligros de volar demasiado alto o muy bajo, idea a la que el propio Virgilio se ajusta.

La diferencia entre la poética de Virgilio y la de Ovidio es notable. Virgilio decide hablar del laberinto de Creta en un momento clave de la Eneida, cuando Eneas decide hablar con la Sibila para consultarle sobre el viaje que éste desea hacer al inframundo para hablar con su padre. En Virgilio el laberinto representa el respeto que el poeta tiene por las formas establecidas por los dioses (en este caso la noción del medio camino). Es necesario tomar en cuenta todas las connotaciones de lo patriarcal que se 
desprenden de las palabras "modelo" "canónico" y de la figura del padre en sí misma. En Virgilio la palabra "laberinto" tiene su raíz etimológica en la palabra labor, que significa trabajo, actividad comúnmente relacionada con el padre. Como bien lo menciona Pavlock, la composición de la Eneida es "a complex pattern". Entre los varios significados de la palabra inglesa "pattern" se encuentran "modelo" o "patrón". Es decir, el poema de Virgilio, "maze-like", es una complicada composición de modelos. Además, la palabra labor también se relaciona con la idea de "empresa", es decir, una tarea ardua y dificultosa. Virgilio, en su descripción del laberinto construido por Dédalo, sugiere que la poesía debe ser una construcción compleja que requiere una tarea ardua: "hic labor ille domus et inextricabilis error" (VI: 27).

La descripción de Virgilio no ahonda en la descripción del mito de Ícaro: "tu quoque magnam/partem opere in tanto, sineret dolor, Icare, haberes/bisconatus erat casus effingere in auro, /bis patriae cecidere manus" (VI: 30-33), mientras que Ovidio sí. Como explica Pavlock, Ovidio crea un contraste entre una labor creativa seria, representada en Dédalo, y la actividad curiosa y alegre representada en Ícaro:

\section{El niño Ícaro, junto \\ Se estaba e, ignora de que él los peligros suyos trataba, Ora, luciente el rostro, las plumas que el aura moviera, Vagas, cogía; ora con el pulgar la cera amarilla Ablandaba, y con su juego la obra admirable del padre Impedía (VIII: 195-200).}

En las Metamorfosis, la poesía, como Virgilio la concibe, está representada en Dédalo mientras que la poesía según Ovidio está representada en Ícaro.

Como se mencionó con anterioridad, la labor del hombre piadoso, y por lo tanto sabio (esta labor por supuesto se extiende al poeta), es mantenerse dentro de la naturaleza de lo que corresponde a su esencia. Dédalo decide olvidarse de los dioses y emprender el vuelo con sus propios medios: "que no a Bootes tú mires, / O a Hélice, te mando, y de Orión a la espada empuñada, / Yo guía, toma el camino" (VIII: 206-208). Como se ve, esta resolución será la que lo convertirá, a los ojos de los dioses, en un ser arrogante e impío. Este hecho prefigura su tragedia, es decir, la caída de Ícaro.

El mito de Ícaro juega, de igual forma, un rol fundamental en la poética de James Joyce. El verso et ignotas animus dimitit in artes (y envía a ignotas artes su ánimo) es la quintaesencia de la visión del arte de Joyce. En El retrato del artista adolescente la figura del artífice - la figura de Dédalo — se le presentará al joven Stephen como una premonición de su destino: “ ¡Bous Stephanoumenos! ¡Bous Stephaneforos! [...] Now as never before, his strange name seemed to him a prophecy" (Joyce: 173). Stephen reconoce en el nombre de Dédalo su verdadera vocación pues descubre que desea apartarse de la religión para emprender la carrera del arte: "Esteban ha dejado de invocar a Dios e invoca al artesano primitivo de su oficio [...] como a un santo patrón. Se emancipa de un dogma para servir a la más rigurosa disciplina" (Marichalar: XXII). 
Sin embargo, algunos momentos después, el artista en ciernes se da cuenta de que todo aspirante a Dédalo corre el riesgo de convertirse en un Ícaro: "Now, at the name of the fabulous artificer, he seemed to hear the noise of dim waves and to see a winged formflying above the waves and slowly climbing the air" (Joyce: 173).

Joyce invoca los roles gemelos del artífice (Dédalo) y del aprendiz (Ícaro):

His heart trembled; his breath came faster and a wild spirit passed over his limbs as though he was soaring sunward. His heart trembled in an ecstasy of fear and his soul was in flight. His soul was soaring in an air beyond the world and the body he knew was purified in a breath and delivered of incertitude and made radiant and commingled with the element of the spirit. An ecstasy of flight made radiant his eyes and wild his breath and tremulous and wild and radiant his windswept limbs.

-One! Two!... Look out!

—Oh, Cripes, I'm drownded! (174).

El artista de Joyce se eleva en "una atmósfera que no es de este mundo". Stephen Dedalus, como el Ícaro de Ovidio, juega a ser un dios en el momento en que se siente "confundido" "en el elemento del espíritu". No obstante, la voluptuosidad que acompaña la revelación del llamamiento de Dedalus se ve súbitamente interrumpida por una acción de orden banal: “¡Oh, Cripes, I'm drowned!” Esta interrupción de su éxtasis le recuerda a Stephen su posible caída.

Ovidio representa a Ícaro en su intento "audaz" por conseguir llegar al cielo. En este sentido, Barbara Pavlock encuentra un paralelismo entre esta escena y la caída de Faetón, ya que tanto Faetón como Ícaro pierden la vida arrastrados por la ambición de llegar al sol. Pavlock, siguiendo la lectura de V. M. Wise en "Flight Myths in Ovid's Metamorphoses", explica que ambos mitos tienen dos aspectos en común: por un lado, en los dos mitos el vuelo se entiende como una metáfora de la creación artística; por el otro, en ambos casos los padres (Febo y Dédalo) son incapaces de disuadir a sus hijos de permanecer dentro del "medio camino".

Cuando el niño empezó en el vuelo audaz a gozarse,

y abandonó al guía y arrastrado del ansia del cielo,

Condujo más alto el camino. La vecindad del sol rápido

Ablandó, perfumadas, vínculos de las plumas, las ceras;

Las ceras se habían fundido; él sacude desnudos los brazos,

Y, carente de remo, no recoge auras algunas,

Y sus bocas que claman el nombre paterno, tomadas

Son del agua cerúlea, que de aquél atrajo su nombre.

Mas el padre infeliz, y ya no padre: "Ícaro — dijo-;

Ícaro — dijo-; ¿dónde estás? ¿Te buscaré en qué región?

Ícaro", decía. Percibió en las ondas las plumas

Y maldijo sus artes (Ovidio, VIII: 223-234).

Joyce y Ovidio ven en las "artes oscuras" la esencia del artista. Del mismo modo que el Dédalo de Ovidio, Stephen Dedalus intentará renovar la naturaleza por medio 
de un artificio. Dedalus necesita las alas del arte para escapar de todo aquello que le oprime y constriñe en Irlanda: su nación, sus amigos, su familia y su religión. En palabras de Antonio Marichalar: "El drama de Dédalus es el esfuerzo de un espíritu obstinado en sobrepasarse, en superar los límites que le imponen su nacimiento, su educación, su nacionalidad. Propónese, para conseguirlo, un tipo ideal, y —al amor del arte- tiende hacia él" (XXIII).

La novela de Joyce al igual que las alas que construye Dédalo, de acuerdo con la descripción de Ovidio, va surgiendo poco a poco de "elementos dispares": en este caso los diferentes registros del habla que conforman la novela. Lo que tanto Joyce como Ovidio saben es que intentar alcanzar el ideal en el arte conlleva un riesgo muy alto. En el caso de Ovidio su intención por imitar a la naturaleza en su constante cambio puede haber ido demasiado lejos como para garantizarle el escarnio y la burla. Como Ícaro y Dédalo, Ovidio sabe que él es un mortal y que su lugar no pertenece al éter: "A éstos, alguien, mientras coge peces con la trémula caña, / $\mathrm{O}$ un pastor en su báculo o un arador apoyado en su esteva, / Vio y se pasmó, y los que tomar el éter podían, /Creyó que eran dioses" (VIII: 217-220). Sin embargo, como se ve, decide emularlos. En el caso de Joyce es más fácil percibir su alejamiento de las esferas celestiales, o de cualquier otra entidad con connotaciones patriarcales, dada su confesión de orden diabólico non serviam: "I will not serve that in which I no longer believe whether it call itself my home, my fatherland or my church: and I will try to express myself in some mode of life or art as freely as I can and as wholly as I can, using for my defense the only arms I allow myself to use-silence, exile, and cunning" (248). Si Ovidio decide alejarse del orden que le impone la naturaleza y por tanto los dioses, el artista de Joyce decide liberarse de esa autoridad que le instan las instituciones. Para Stephen Dedalus someterse a las instituciones le representa no superar la "mediocridad", no en su sentido negativo, sino en su sentido de "medianía", lo que para Joyce es una suerte de medio de camino a la excelencia. En Ovidio el principio "mediocritas" tiene su representación, como se dijo con anterioridad, en el mito de Ícaro (el medio camino) pero también en el mito de Perdiz, aquel sobrino de Dédalo, que en recuerdo de su caída hace sus nidos justo en mitad de los árboles, a mediana altura.

Al final de su trabajo, Barbara Pavlock concluye que, a pesar de que muchos estudiosos de Ovidio, como Alison Sharrock, ven en él un reflejo del poeta Calímaco, quien a pesar de admirar a Homero prefiere una poesía libre de excesivos adornos, es decir, una poética de la "medianía", la poética de Ovidio explicita querer ir más allá: "Ovid picks up where the ekphrasis in the Aeneid leaves off, for Vergil concludes his account of Daedalus by noting what is absent: tu quoque magnan / partem opere in tanto, sineret dolor, Icare haberes (30-31)... whereas for Virgil it is too dificult to portray the fall of Icarus, Ovid elaborates on it" (147).

Pareciera que tanto para Ovidio como para Joyce el verdadero artista es aquel que por curiosidad y por necesidad se aleja del orden establecido. Ovidio, como sugiere Pavlock, privilegia la palabra lusus sobre la palabra labor para proponer un ejercicio poético más libre y fluido. Aunque, en principio, el poeta latino censura el proceder 
de Dédalo, quien, olvidándose de la voluntad de los dioses, decide utilizar sus propios medios para evadirse de su exilio, después parece hacer una confesión velada de su postura real: la del artesano que debe retar la noción de piedad y su problemática noción paternal. Por su lado, Joyce se sabe un vanguardista y como vanguardista sabe que necesita alejarse de los modelos y patrones establecidos. Joyce sabía muy bien de lo que hablaba, y conocía muy bien la raíz de las palabras. Sabía qué patrón proviene del latín patronus, que significa protector. En este sentido, sabe que todo aquel que se aleja del patrón está expuesto a despeñarse de un momento a otro. Para Joyce el artista es aquel que "envía su ánimo hacia "artes desconocidas" porque el verdadero artista, como Ícaro, se va forjando a través de la experiencia: "O life! I go to encounter for the millionth time the reality of experience and to forge in the smithy of my soul the uncreated conscience of my race" (253). Para Joyce el destino del artista es siempre trágico: "I am not afraid to make a mistake, even a great mistake, a lifelong mistake and perhaps as long as eternity too" (248).

\section{Obras citadas}

Bonifaz, Rubén, trad. "Introducción". Metamorfosis. Por Publio Ovidio Nasón. México: UNAM, 1979. VII-CLV. Impreso.

HAMMER, Langdon. "Introduction". A portrait of the Artist as a Young Man". Por James JoYCE. Nueva York: Signet Classics, 1991. Pp. 7-18. Impreso.

JoYCE, James. A Portrait of the Artist as a Young Man. Nueva York: Signet Classics, 1991. Impreso.

MARICHALAR, Antonio. "James Joyce y su laberinto". El retrato del artista adolecente. Por James JoYCE. México: Porrúa, 2001. Pp. IX-XXV. Impreso.

Ovidio Nasón, Publio. Metamorfosis. Trad. Rubén Bonifaz NuÑo. México: UNAM, 1979. Impreso.

PARKINSON, Louis. "Aproximaciones interartísticas a la lectura de textos verbales y visuales". Aproximaciones lecturas del texto. Comp. Esther COHEN. México: UNAM, IIF, 2005. Pp. 157-156. Impreso.

PAVlock, Barbara. "Daedalus in the labyrinth of Ovid's Metamorphoses". The Classical World. Web. 1 de abril de 2014. <http://www.jstor.org/discover/10. 2307/4352238? uid $=3738664 \&$ uid $=2134 \&$ uid $=2473698987 \&$ uid $=2 \& u i d=70$ \&uid $=3$ \&uid $=2473698977 \&$ uid $=60 \&$ sid $=21103596177871>$.

Virgilio. Eneida. Trad. Rafael Fontán BARREIRO. Madrid: Alianza Editorial, 1990. Impreso. 